\title{
Glycosylated Haemoglobin and Steady-State Mean Blood Glucose Concentration in Type 1 (Insulin-Dependent) Diabetes
}

\author{
P. Aaby Svendsen, T. Lauritzen, U. Søegaard and J. Nerup
}

Summary. Since glucose control and glycosylated haemoglobin varies asyncroneously, we have studied the steady-state relationship between these two factors. In Type 1 (insulin-dependent) diabetic patients with a constant haemoglobin $\mathrm{A}_{1 \mathrm{c}}$ during the preceding 2 years, 15 ambulatory blood glucose profiles during a 5 -week period showed a constant glucose level and provided a precise estimate of the mean blood glucose concentration. In addition, we studied 15 non-diabetic subjects who provided three glucose profiles and had one hae- moglobin $A_{1 c}$ determination performed. A good correlation was found for a curvilinear relationship (haemoglobin $A_{1 \mathrm{c}}=$ $2.07 \times$ mean blood glucose ${ }^{0.596}, r=0.98$ ). This close relationship indicates that glycosylated haemoglobin is a valuable, but not very sensitive, index of glucose control.

Key words: Long-term mean blood glucose concentration, glycaemic control, haemoglobin $\mathrm{A}_{1 \mathrm{c}}$, Type 1 diabetes.
In the majority of insulin-treated Type 1 diabetic patients, blood glucose concentrations fluctuate considerably, making precise assessment of long-term glycaemic control in the average outpatient very difficult to obtain. For this reason, long-term glycaemic control might be more precisely reflected by the glycosylated fraction of haemoglobin. Several reports have shown significant correlations between glycosylated haemoglobin and expression of metabolic control in cross-sectional as well as longitudinal studies [1-7]. Most studies reported r-values below 0.9 implying that a given concentration of glycosylated haemoglobin may result from varying degrees of glucose control. Obviously, this makes the usefulness of glycosylated haemoglobin determination in the assessment of long-term glycaemic control in the individual patient rather doubtful.

Since stable haemoglobin $\mathrm{A}_{1 \mathrm{c}}\left(\mathrm{HbA}_{1 \mathrm{c}}\right)$ responds slowly to changes in glucose control $[8,9]$, it might be that the real connection between integrated glucose control and $\mathrm{HbA}_{1 \mathrm{c}}$ in Type 1 diabetic subjects can be established only in patients known to be in stable glucose control over a long period of time.

To test this possibility, we have studied the correlation between mean blood glucose concentration and stable $\mathrm{HbA}_{1 \mathrm{c}}$ in diabetic patients with stable metabolic control for many weeks.

\section{Subjects and Methods}

\section{Subjects}

Of 38 randomly selected insulin-treated diabetic outpatients (age: 15-81 years, duration of diabetes: 3-37 years) in whom several $\mathrm{HbA}_{1 \mathrm{c}}$ determinations had been performed over a 2-year period, 15 patients had six or more $\mathrm{HbA}_{1 \mathrm{c}}$ determinations showing a coefficient of variation of $<10 \%$ (mean $5.2 \%$ ). Detailed information about the patients is given in Table 1.

These 15 patients consented to collect 15 profiles of seven samples each for blood glucose determination over a 5-week period. $\mathrm{HbA}_{1 \mathrm{c}}$ was determined again immediately after the study period and this value was used in the correlation analysis. Fifteen non-diabetic volunteers (eight women, seven men) from the hospital staff served as control subjects and provided three seven-sample profiles and had one $\mathrm{HbA}_{1 \mathrm{c}}$ determination performed.

\section{Methods}

At home patients and control subjects collected seven $10 \mu \mathrm{l}$ blood samples per day by finger-pricking, using insulin-injection needles and $10 \mu \mathrm{l}$ end-to-end capillaries. Samples were obtained $30 \mathrm{~min}$ before and $90 \mathrm{~min}$ after the three main meals and at bedtime. Reagents of the Glucoquant-Haemolysate system (Boehringer, Mannheim, FGR) were used to stabilize glucose during mailing by ordinary mail to our institute and for determination of glucose in the hospital laboratory. The results of glucose determinations obtained by the Glucoquant system were compared with the routine laboratory method [10] in two ways, (1) single samples taken by 41 patients were compared 
Table 1. Clinical details of 15 insulin-treated diabetic patients

\begin{tabular}{|c|c|c|c|c|c|c|c|c|c|c|c|}
\hline \multicolumn{2}{|c|}{ No. of patients } & \multicolumn{2}{|c|}{ Age (years) } & \multicolumn{2}{|c|}{$\begin{array}{l}\text { Diabetes duration } \\
\text { (years) }\end{array}$} & \multicolumn{2}{|c|}{$\begin{array}{l}\text { Insulin dose } \\
\text { (IU/ kg) }\end{array}$} & \multicolumn{2}{|c|}{$\begin{array}{l}\text { No. of patients } \\
\text { injections/day }\end{array}$} & \multicolumn{2}{|c|}{$\begin{array}{l}\% \text { of ideal } \\
\text { body mass }\end{array}$} \\
\hline Women & Men & Mean & Range & Mean & Range & Mean & Range & 1 & 2 & Mean & Range \\
\hline 8 & 7 & 41 & $14-70$ & 8.6 & $2-29$ & 0.57 & $0.14-1.0$ & 5 & 10 & 95 & $86-109$ \\
\hline
\end{tabular}

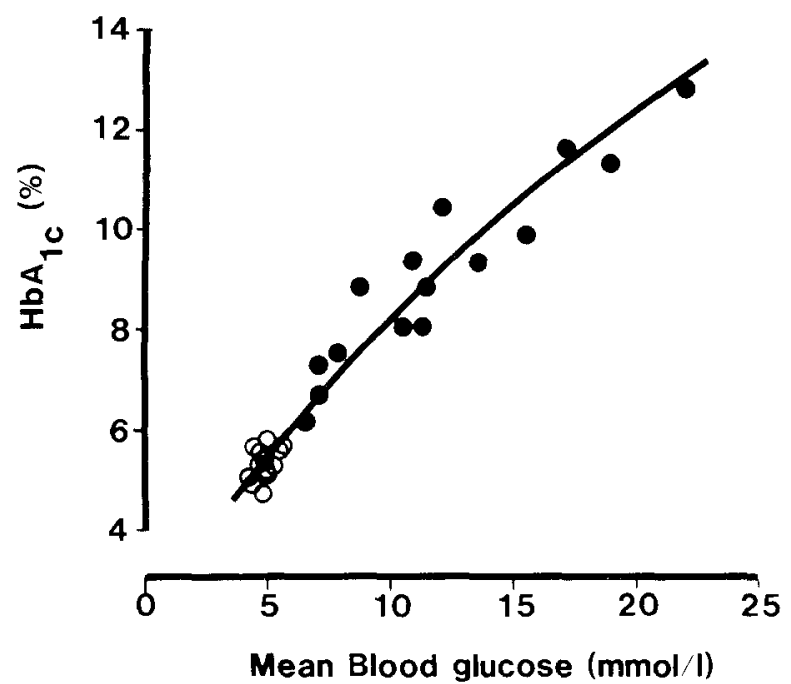

Fig. 1. The correlation between $\mathrm{HbA}_{1 \mathrm{c}}$ and mean blood glucose concentration in 15 non-diabetic control subjects $(O)$ and 15 insulintreated diabetic out-patients $(\bullet)$. The curve drawn is calculated from the regression equation $\mathrm{HbA}_{1 \mathrm{c}}=2.07 \times$ mean blood glucose $\mathrm{e}^{0.596}$

with the routine laboratory method on blood taken simultaneously by laboratory technicians and (2) mean blood glucose values obtained by the two methods of blood sampling and analysis were compared on the basis of six-sample profiles in 28 patients. Daily mean blood glucose values were calculated as the arithmetic mean of all samples a day and the overall mean blood glucose and its variation for each patient and control calculated from daily mean blood glucose values.

To ensure that seven-sample profiles accurately reflect the $24-\mathrm{h}$ mean blood glucose values, mean blood glucose values from sevensamples were compared with mean blood glucose values calculated from 31-sample profiles in 34 Type 1 diabetic patients, where both sets of samples were obtained.

Stable $\mathrm{HbA}_{1 \mathrm{ic}}$ was determined as described previously [11] after incubation of blood samples diluted fivefold in saline $(0.15 \mathrm{~mol} / 1)$ for $6 \mathrm{~h}$ at $37^{\circ} \mathrm{C}$. A fresh blood sample from one non-diabetic person was determined in all analytical series and showed a day-to-day variation of $3.6 \%$ (coefficient of variation) during the study period. $\mathrm{HbA}_{1 \mathrm{c}} \mathrm{re}-$ sults are expressed as percentage of total haemoglobin. Linear and curvilinear regression analyses were performed using standard programmes of the HP-85 calculator.

Results are expressed as mean \pm SD unless otherwise specified and differences in mean values are tested by the Mann-Witney ranksum test.

\section{Results}

\section{Mean Blood Glucose Estimates}

Comparison between glucose values from samples taken by patients (Glucoquant Haemolysate system) and laboratory method demonstrated good agreement between the two methods. The 41 single samples gave values only $0.01 \pm 0.71 \mathrm{mmol} / 1$ lower in the Glucoquant system and also the 28 single day, six-sample mean blood glucose values differed only slightly (on average $0.1 \pm 0.5 \mathrm{mmol} / \mathrm{l}$ ). These differences were considered unimportant. Mean blood glucose values calculated from seven-sample profiles in 34 Type 1 diabetic patients were slightly higher than mean blood glucose values calculated from 31-sample profiles taken on the same day (the mean difference being $0.4 \pm$ $1.1 \mathrm{mmol} / \mathrm{l}$ ). This difference was considered acceptable.

The mean blood glucose values of the 15 insulintreated out-patients ranged from $6.5-22.0 \mathrm{mmol} / 1$ with standard deviations ranging from $0.8-4.3 \mathrm{mmol} / 1$. The difference between the mean of all glucose values from the first and last 2 weeks of the study period was significant in three patients only. No difference was found when daily mean blood glucose values were compared for the two periods and therefore we considered most patients to have a constant glucose level. In the 15 control subjects, the standard deviations of mean blood glucose determinations ranged from 0.03 to $0.5 \mathrm{mmol} / \mathrm{l}$.

\section{$H b A_{\text {Ic }}$ Determinations}

The $\mathrm{HbA}_{1 \mathrm{c}}$ values for the 15 patients ranged from $6.2-12.8 \%$. The control subjects had values ranging from $4.7-5.8 \%$, i. e. within the normal range (4.1-6.4\%) for our laboratory.

\section{The Mean Blood Glucose-HbA $A_{l c}$ Relationship}

Figure 1 shows the results of mean blood glucose- and $\mathrm{HbA}_{1 \mathrm{c}}$-values plotted against each other. For the combined material of Type 1 diabetic and control subjects, the coefficient of correlation was highest for the curvilinear correlation $\left(\mathrm{HbA}_{1 \mathrm{c}}=2.07 \times\right.$ mean blood glu$\left.\operatorname{cose}^{0.596}, r=0.98\right)$.

\section{Discussion}

In most insulin-treated Type 1 diabetic patients, blood glucose concentrations vary greatly within as well as between days. Long-term assessment of diabetic control in Type 1 diabetic patients based upon glucose determinations would require large numbers of 24 -h profiles produced by large numbers of blood glucose determina- 
tions, thus being difficult to obtain, expensive and rather demanding for the patients.

Since $\mathrm{HbA}_{1}$ seems to reflect integrated blood glucose control over long periods of time [12], we found it of interest to investigate whether the varying correlations between different parameters of glucose control and $\mathrm{HbA}_{1}$ fractions reported so far [1-7] might be due to lack of precision of the mean blood glucose estimates in the typical insulin-treated diabetic patient.

By studying patients expected to be in relatively stable blood glucose control and by frequent sampling of seven sample blood glucose profiles, we were able to demonstrate a very strong and curvilinear correlation between mean blood glucose and stable $\mathrm{HbA}_{1 \mathrm{c}}(r=$ 0.98).

A slightly curved relationship between mean blood glucose and $\mathrm{HbA}_{1 \mathrm{c}}$ is predicted by the mathematical model proposed by Beach [13] and has been proposed by others [5-7] on the basis of clinical observations. However, most of the coefficients of correlation reported so far were too low to allow the use of $\mathrm{HbA}_{1 \mathrm{c}}$ determination as a precise tool in the assessment of mean blood glucose or long-term glycaemic control in the individual out-patient Type 1 diabetic. The biological significance of the curvilinear relationship is unknown, but it does make $\mathrm{HbA}_{1 \mathrm{c}}$ a somewhat insensitive index of integrated blood glucose control in the higher range of mean blood glucose levels. The obvious practical consequence of the curved relationship is that it is necessary to introduce $\mathrm{HbA}_{1 \mathrm{c}}$ assays with high analytical specificity and precision.

Our results demonstrate that mean blood glucose may be precisely estimated from one $\mathrm{HbA}_{1 \mathrm{c}}$ determination in insulin-treated diabetic patients with a constant mean blood glucose level. In ongoing studies, we have observed that patients in whom mean blood glucose values are calculated from less frequently sampled profiles and selected on the basis of (1) constant subcutaneous insulin infusion, (2) retinopathy, (3) nepropathy, and (4) $\mathrm{HbA}_{1 \mathrm{c}}$ values above $10 \%$, also scattered around the regression curve found in this study.

Acknowledgements. We thank Mrs. A. Rafn for excellent secretarial assistance.

\section{References}

1. Gonen B, Rochman H, Rubenstein AH, Tanega S (1977) Haemoglobin $A_{1}$ : an indicator of the metabolic control of diabetic patients. Lancet II : 734-736

2. Berger W, Sonnenberg GE (1980) Blutzuckertagesprofile and Hämoglobin $A_{1}$ zur Überwachung der Diabetesbehandlung. Schweiz Med Wochenschr 110: 485-491

3. Paisey RB, MacFarlane DG, Sherriff RJ, Hartog M, Slade RR, White DA (1980) The relationship between blood glycosylated haemoglobin and home capillary blood glucose levels in diabetics. Diabetologia 19: 31-34

4. Daubresse JC, Lemy C, Bailly A, Meunier JC (1979) The usefulness of a rapid method for total fast haemoglobin determination in screening for diabetes control. Diabete Metab : 5: 301-305

5. Graf RJ, Halter JB, Porte D (1978) Glycosylated haemoglobin in normal subjects and subjects with maturity onset diabetes. Diabetes 27: 834-839

6. Topper E, Doron M, Karp M, Laron Z (1979) Relationship between glycosylated haemoglobin and postprandial blood glucose in insulin-dependent juvenile diabetes patients. Isr J Med Sci 15: 283-284

7. Stanton KG, Davis RE (1978) The relationship between the control of diabetes mellitus and circulation glycosylated haemoglobin $\mathrm{A}_{1}$. Aust NZ J Med 8: 400-404

8. Koenig RJ, Peterson CM, Jones RL, Saudek C, Lehrman M, Cerami A (1976) Correlation of glucose regulation and haemoglobin $A_{1 c}$ in diabetes mellitus. N Engl J Med 295: 417-420

9. Peterson CM, Jones RL, Dupuis A, Levine BS, Bernstein R, O'Shea M (1979) Feasibility of improved glucose control in patients with insulin-dependent diabetes mellitus. Diabetes Care 2: 329-335

10. Trinder P (1969) Determination of blood glucose using glucose oxidase with an alternative oxygen acceptor. Ann Clin Biochem 6: 24-27

11. Svendsen PA, Christiansen JS, Søegaard U, Welinder BS, Nerup J (1980) Rapid changes in chromatographically determined haemoglobin $A_{1 c}$ induced by short-term changes in glucose concentration. Diabetologia 19:130-135

12. Dunn PJ, Cole RA, Soeldner JS, Gleason RE (1981) Stability of haemoglobin $A_{1 c}$ levels on repetitive determination in diabetic out-patients. J Clin Endocrinol Metab 52: 1019-1022

13. Beach KW (1979) A theoretical model to predict the behaviour of glycosylated haemoglobin levels. J Theor Biol 81 : 547-561

Received: 2 September 1981

and in revised form: 16 June 1982

Per Aaby Svendsen

Steno Memorial Hospital

DK-2820 Gentofte

Denmark 